\title{
Integrating Crane Information Models in BIM for Checking the Compliance of Lifting Plan Requirements
}

\author{
Justin K.W. Yeoh ${ }^{\mathrm{a}}$, J.H. Wong ${ }^{\mathrm{a}}$ and L. Peng ${ }^{\mathrm{a}}$ \\ ${ }^{a}$ Department of Civil and Environmental Engineering, National University of Singapore, Singapore \\ E-mail: justinyeoh@nus.edu.sg, A0088544@u.nus.edu, peng_le@u.nus.edu
}

\begin{abstract}
Cranes typically represent the single biggest equipment investment deployed on a construction site. The success of lifting operations depends on addressing project conditions and adequate site safety management. The Crane Lifting Plan (CLP) is a safety document wherein the information required for planning crane lifting operations are encapsulated and analyzed. A range of regulatory, safety and operational requirements must be complied with. Chief among these considerations is the correct selection and siting of cranes to support the lifting operations. The current practice of developing and checking a CLP is a manual, tedious and potentially error-prone process. Recent advances in Building Information Modeling (BIM) may help to address these difficulties. This paper presents a formalized representation framework for CLP requirements. A parametric Crane Information Model, which enables various regulatory and safety information to be incorporated is also developed. The result of this paper is a step towards automatically checking the compliance of CLP requirements. Finally, a case study of an academic building is used to validate the proposed framework.
\end{abstract}

Keywords -

Crane Lifting Plans; Crane Information Model; Regulatory Compliance; Construction Requirements

\section{Introduction}

In Singapore, static cranes are commonly deployed in high-rise projects, of which the two common types are Tower Cranes and Luffing Jib Cranes. The densely builtup urban environment in Singapore constrains the deployment of these construction equipment, creating significant construction challenges to contractors, and compliance issues to the regulatory authorities.

Moreover, cranes typically represent the single biggest equipment investment deployed on a construction site [1], and are also one of the main sources of hazards on site [2]. Statistics from the Workplace Safety and Health Institute (Singapore) [3] show that crane related incidents accounted for almost $20 \%$ of all fatalities in the construction industry from 2011 to 2014.

Shapira et al. [4] studied the various factors affecting the safe use of cranes on site, and reported that site safety management, as well as the various project conditions are major determinants. The Crane Lifting Plan (CLP) is a safety document wherein the information required for planning crane lifting operations are encapsulated and analyzed [5]. This involves a range of regulatory, safety and operational requirements which must be complied with to address the project conditions and site safety management issues. Chief among these considerations is the correct selection and layout/siting of cranes to support the lifting operation, subject to the contractor's cost constraints. The current practice of developing a CLP is a manual, tedious and potentially error-prone process [6]. Similarly, checking the CLP for compliance is often difficult, and the consequences of an erroneous CLP could be disastrous, resulting in major accidents and fatalities onsite.

Several research challenges exist which need to be addressed. The first is the need to represent CLP requirements in a form that is usable for analysis. This paper overcomes this challenge by developing a formalized representation of CLP requirements. The second challenge is to capture generic parametric information of a crane. Such a generic information representation schema should allow for different crane types to be modeled. Recent advances in Building Information Modeling (BIM) may help to address this challenge. This paper introduces a Crane Information Model (CIM) which will embed the crane information within BIM for analysis.

This paper starts with a literature review of the current methods for workspace analysis, as well as current crane analysis techniques, and code compliance. The next section details the identification of workspaces from common CLP requirements using a formalized approach. These identified workspaces are then incorporated into a Crane Information Model (CIM), with the purpose of reducing the errors during CLP. The result of this paper 
is a step towards automatically checking the compliance of CLP requirements. This is validated via a case study.

\section{Relevant Literature}

\subsection{Representing and Analyzing Workspaces for Construction Operations}

Various methodologies for modeling construction workspaces exist. These have been proposed for the analysis of spatial conflicts, and the primary method of conflict detection is the analysis of interferences.

Riley and Sanvido [7] identified 13 types of spaces required by construction activities: building components, layout areas, unloading areas, material paths, personnel paths, storage areas, staging areas, prefabrication areas, crew areas, tool and equipment areas, debris paths, protected areas, and hazard areas.

Akinci et al [8] studied the representation of spaces in a 3D CAD environment, and identified the parameters required for representing these spaces. These include: Reference object, volumetric parameters and orientation. A taxonomy of space usage and the resultant conflicts were also developed based on the interactions between spaces [9]. One key contribution is the recognition that not all space interferences constitutes conflict.

Guo [10] analyzed the spatial requirements of movement paths (pathspaces) for workers, equipment and materials on-site. This inclusion of pathspaces, which are abstracted as pathspace requirements (minimum path height and minimum path width) was a separate space type, which could facilitate the verification of the availability of access to work faces.

Chua et al [11] proposed an alternative analysis methodology based on the utilization of space. In their paper, the space taxonomy was differentiated according to the amount of space used. This led to the identification of Product (Dead) spaces, Process/Workspaces and Pathspaces, as well as Interdiction (Clearance) spaces.

$\mathrm{Su}$ and Cai [12] have extended the traditional 3D topological analysis, by enhancing the coupling of time analysis with 3D. This results in a 4D topological relationship analysis technique. The technique is then validated using a crane example to test for crane reach and crane hazard spaces. This validation demonstrated the applicability of determining feasible crane operations from a 3D/4D perspective.

The above methodologies aid the visualization of space utilization among the different construction trades. Such visualization helps engineers to identify possible conflicts arising from the detected space collisions. Thus far, analyzing the crane's workspaces and space requirements for lift planning has not been commonly conducted to the authors' knowledge. Instead, most code compliance approaches focus on building design [13], fire engineering [14] or construction quality [15]. One contribution of this paper is the application of workspace analysis for cranes to regulatory conformance. This entails the identification of spaces for cranes, and the recognition of the conditions leading to spatial conflicts during crane operations. These often arise from the interactions of these spaces.

\subsection{Analysis of Static Crane Operations}

The analysis of static crane operations is also widely studied in the literature. Analyzing static crane operations is one of the fundamental activities in a CLP. In general, there have been several approaches used: Mathematical models, and Simulation.

The mathematical models are often formulated to optimize some quantitative metric like transportation cost or time. Huang et al [16] noted that the crane layout problem involves various nonlinearities, leading to some of these models being computationally expensive. Various metaheuristic models like genetic algorithms and artificial neural networks [17] have been applied. Such approaches have been successfully applied, but requires that a certain amount of crane and project information be 'hard coded' into the optimization problem.

Other approaches attempted to address the crane layout problem by incorporating 3D visualization with simulation. Such approaches typically incorporate 3D crane models into existing 3D building models, and simulate the workflow of the cranes $[1,18]$. Such simulation models are often difficult to generalize, and may even miss some conflicts if discrete event simulation is employed [19].

Several recent efforts have begun looking at BIM as an information platform. BIM has shown to be extremely useful for providing project information, like sizes and quantities of elements. Irizarry and Karan [20] implemented a GIS-BIM hybrid to reason about suitable crane locations, while Olearczyk et al [21] employed a BIM based methodology for modular construction. Marzouk and Abubakr [22] and Wang et al [23] have also leveraged BIM to mitigate the difficulties of incorporating site information for layout planning.

\section{Research Approach: Identifying Information Requirements for Automating CLP}

To address the problem of automating a CLP, the research approach adopted in this paper looks to identify the various information requirements needed. Three information requirements are identified (Figure 1): The first information requirement is BIM. BIM should 
encompass the 3D facility information, the site layout plan, temporary structures, material delivery and construction phasing plan. This information requirement is assumed to be available in this research.

The second information requirement is the identification of the relevant crane codes and regulations. This has to be translated into a formalized representation, so that automation can be conducted. This second requirement forms the basis for the following section.

The third information requirement is the identification of the relevant crane parameters and information. This will include the loading characteristics of the available cranes on the market, which is obtainable from the respective load charts, as well as the relevant crane geometry. This third requirement is addressed in the following sections of this paper.

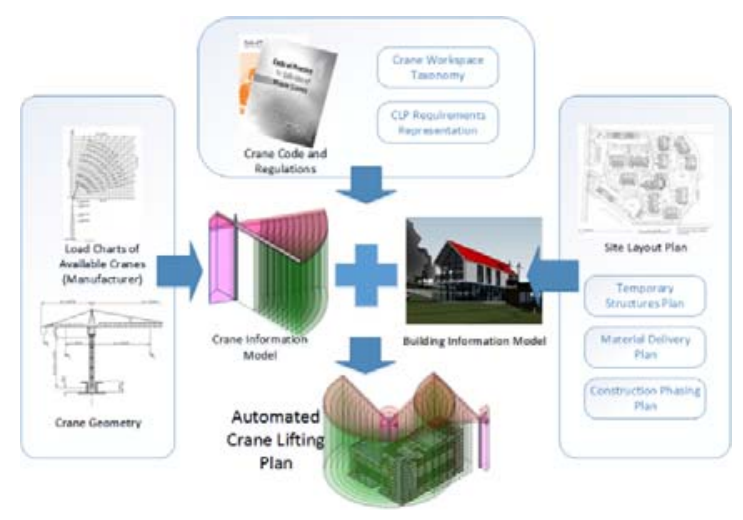

Figure 1. Information Requirements for Automated Crane Lifting Plan

\section{Identifying and Modeling Workspaces from Common CLP Requirements}

This section discusses the formalized representation of some CLP requirements by starting with a framework for representation, a space taxonomy for crane workspaces, and finally a summary of some common CLP requirements in Singapore.

\subsection{A Space Taxonomy for representing CLP Requirements}

Song and Chua [24] introduced a formal framework to represent functional construction requirements, and this framework was extended by Yeoh and Chua [25] to incorporate non-functional requirements as well. These construction requirements may be described as capabilities and conditions for which the construction process must conform to. CLP requirements are a subset of these construction requirements.
The representation framework adopted in this paper has been adapted from [25] and includes the following elements: A function (requirement) user, a function (requirement) provider, and the necessary condition (relationship) between the function user and function provider.

Two types of requirements are identified for CLP: Spatial and Parametric. In the spatial requirement (Figure 2 ), the function user is defined as the requester of the function, while the function provider describes the conditions for fulfilling the requirement. Each function user and function provider is comprised of a set of 3D spaces. In the CLP context, an example of a user and provider could be the Crane and Building respectively. The necessary condition then describes the interaction between both the provider and user via set operators. In particular, this relationship describes the failure conditions of the requirement, i.e. the conditions under which the requirement is not fulfilled.

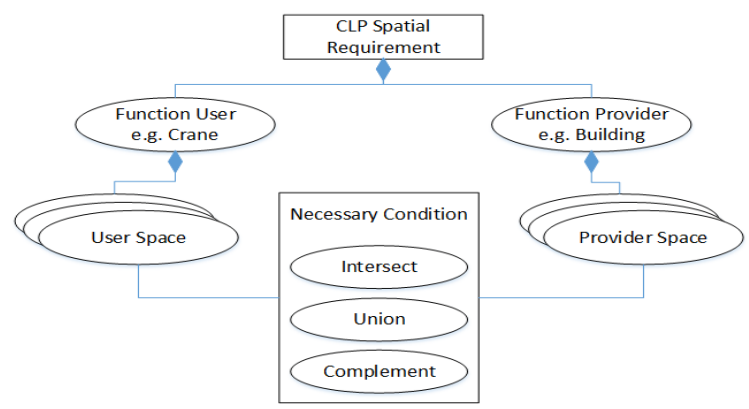

Figure 2. Crane Lifting Plan Spatial Requirements Representation Framework

The second requirement is the parametric requirement (Figure 3). This requirement is similar to that in Figure 2, except that the parameters used to describe the Function User and Function Provider are compared to determine the conditions of failure for the requirement. Mathematical operators are used in place of set operators, as this allows for manipulation and comparison of the parametric values.

Figure 4 shows the space taxonomy related to the requirements. Following the characterization of space utilization in Chua et al [11], three main classes of space are identified: Hazard space, Process space and Product space. The spaces in CLP requirements originate from three sources: Site, Building Facility, and Crane.

The crane and building structure are examples of a product space, and describe the physical elements of the crane and building. The crane working envelope is a type of process space. It is the union of the different possible jib positions of the crane, and its corresponding zone of operation. Building process spaces include the path and activity spaces. 


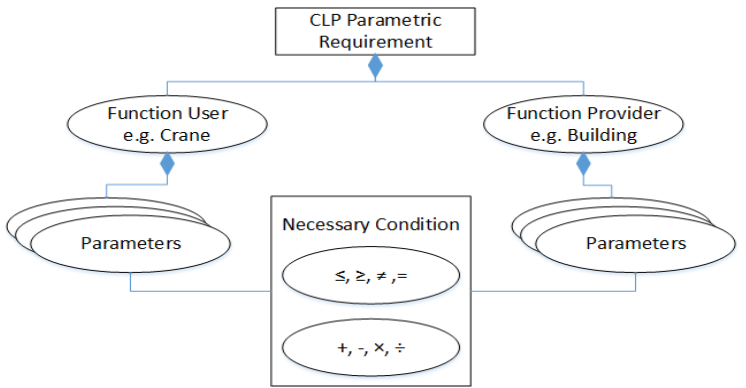

Figure 3. Crane Lifting Plan Parametric Requirements Representation Framework

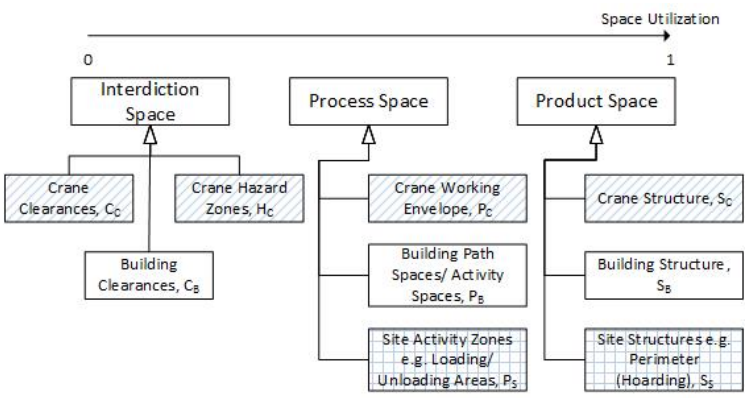

Figure 4. Space Taxonomy for CLP Requirements

The interdiction spaces are spaces where no space utilization is allowed. Two types of interdiction spaces are possible: Clearances and Hazards. Clearance spaces are meant to denote protective zones against physical elements. Clearance spaces include buffer areas around physical elements. Hazard zones (spaces) are used to demarcate areas of hazardous operations. Examples of hazard zone include the zone under the counterweight of the counter-jib.

\subsection{Identifying Common CLP Requirements}

The above taxonomy aids in allowing common CLP requirements to be represented in a manner useful for analysis. The advantage is that conflict detection in the requirements for crane operations becomes automated.

To illustrate the applicability of the representation framework, the following obvious crane requirement is used: "The crane structure should not be co-located with the building structure". In other words, the crane must not occupy the same space as any of the elements in the building structure.

The Function User is identified as the Crane, while the Function Provider is identified as the Building. Using the space taxonomy provided, the spaces associated with the User and Provider are identified: Crane Structure and Building Structure respectively. To fulfil the intention of the requirement, the Necessary Condition is that both crane structure and building structure must not intersect.

Table 2 presents a list of common CLP requirements found in the relevant Code of Practice in Singapore [5], as well as common operational considerations. This table uses a dot notation to display the spaces or parameters of the Function User and Function Provider, e.g. User.Space or Provider.Parameter. An ID for each space or parameter is also provided in parenthesis. This notation is then used to describe the Necessary Condition to evaluate for non-compliance.

The result of conducting this formalization of CLP requirements is the ability to analyze crane and building information models, and evaluate non-compliances.

\section{Crane Information Model (CIM)}

The Crane Information Model (CIM) is developed based on several requirements: Firstly, CIM was intended to be an extension of current BIM systems. This means that elements, and spaces within CIM should be parametrically driven. This will allow CIMs to be easily modified and collaboratively shared. Secondly, CIM is intended to be a repository of crane information. Hence, the relevant crane information should incorporate not only the crane geometry, but the load charts as well.

The following models were created as Autodesk Revit Families, where the parametric crane information were entered as Revit Family parameters to automatically generate the model geometry.

\subsection{Mapping Parametric Information to Crane Spaces}

Some of the basic parameters of a static crane are presented in the following Table 1 . These basic parameters allow static crane information to be easily modified to suit specific project requirements. Additionally, Table 1 provides a schematic mapping showing the relationship between the real crane parameters to the corresponding crane spaces. The source of information for these parameters is also provided in Table 1. Some are user-defined, while others arise from regulatory compliance, crane catalogues, or project specific information, or a combination thereof. These parameters thus drive the geometric and information properties of the crane spaces.

The load chart information of the cranes are also embedded into the CIM via the workspace envelope. The workspace envelope is discretized, with each discrete section having a corresponding load capacity. To illustrate this, an example of a tower crane load chart is shown in Figure 5. The load capacity is typically dependent upon the jib length for the tower cranes. This 
also typically holds for luffing jib type tower cranes.

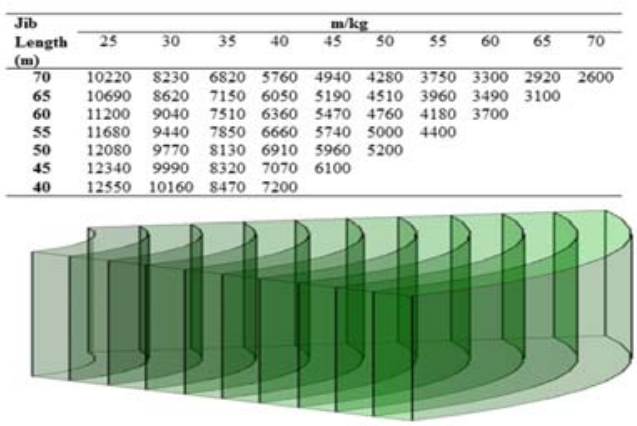

Figure 5. Relating Load Chart information to Workspace Envelope

Table 1. Static Crane Parameters. $(*)$ represents information for Luffing Jib Type Crane

\begin{tabular}{|c|c|c|c|}
\hline & Parameter & Type & Source* \\
\hline Crane & Total Height & Length & $\mathrm{U} / \mathrm{C}$ \\
\hline \multirow[t]{8}{*}{ Structure } & Mast Height & Length & $\mathrm{U} / \mathrm{C}$ \\
\hline & Head Height & Length & $\mathrm{C}$ \\
\hline & Hook Height & Length & $\mathrm{C}$ \\
\hline & Jib Length & Length & $\mathrm{U}$ \\
\hline & $\begin{array}{l}\text { Counter Jib } \\
\text { Length }\end{array}$ & Length & $\mathrm{C}$ \\
\hline & Mast Size & Length & $\mathrm{C}$ \\
\hline & Jib Size & Length & $\mathrm{C}$ \\
\hline & Jib Angle* & Angle & $\mathrm{U} / \mathrm{P}$ \\
\hline \multirow{5}{*}{$\begin{array}{l}\text { Workspace } \\
\text { Envelope }\end{array}$} & Coverage Angle & Angle & $\mathrm{U}$ \\
\hline & Base Angle & Angle & $\mathrm{P}$ \\
\hline & Load Capacity & Weight & $\mathrm{C}$ \\
\hline & Hook Weight & Weight & $\mathrm{C}$ \\
\hline & $\begin{array}{l}\text { Load Factor of } \\
\text { Safety }\end{array}$ & Real & $\mathrm{U} / \mathrm{R}$ \\
\hline \multirow{5}{*}{$\begin{array}{c}\text { Interdiction } \\
\text { (Safety) } \\
\text { Space }\end{array}$} & $\begin{array}{c}\text { Jib Clearance } \\
\text { Value }\end{array}$ & Length & $\mathrm{R}$ \\
\hline & Counter Jib & Length & $\mathrm{R}$ \\
\hline & Clearance Value & & \\
\hline & Minimum & Length & $\mathrm{R}$ \\
\hline & $\begin{array}{l}\text { Building Height } \\
\text { Clearance }\end{array}$ & & \\
\hline Orientation & True North & Angle & $\mathrm{P}$ \\
\hline
\end{tabular}

Figure 9 shows the results of the developed CIMs for both Tower Cranes and Luffing Jib Tower Cranes incorporating the various workspace envelopes, crane clearances and hazard areas. Crane parameters are indicated in italics.

\section{Validation: Demonstrating the CLP Requirements for an Academic Building}

An academic building was used as a case study to validate the formalization of requirements as well as to demonstrate the applicability of CIM. The building comprised two adjoining blocks. The first block is a 10 story structure comprising primarily precast elements, of which there are about 210 pieces per story. The second is a 6 story workshop, with about 70 precast elements per story. The largest element, a post tensioned deep beam situated at the auditorium, weighed about 10 tons. The site was also subject to a height restriction of $80 \mathrm{~m}$.

The proposed lifting plan is shown in Figure 6 below. Two tower cranes and a luffing jib crane with specific characteristics as shown in the figure were analyzed.

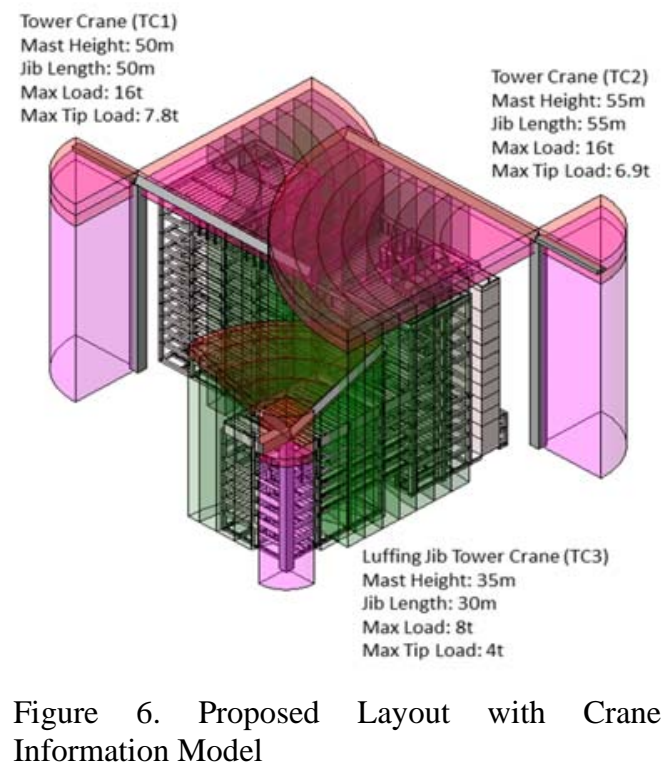

To validate the proposed approach in this paper, the various corresponding requirements in Table 2 were checked in the case study. These checks may be carried out by visual inspection, or by using interference checking or filtering mechanisms commonly found in BIM applications.

\subsection{Requirement 1, 2, 6 and 7: Site Boundary, Counter-Jib Clearance, Crane Coverage and Load Capacity}

Figure 7 shows the plan view of the project site. From this plan view, the site boundary has not been exceeded by the proposed workspace envelopes or the various clearances required by the crane. 


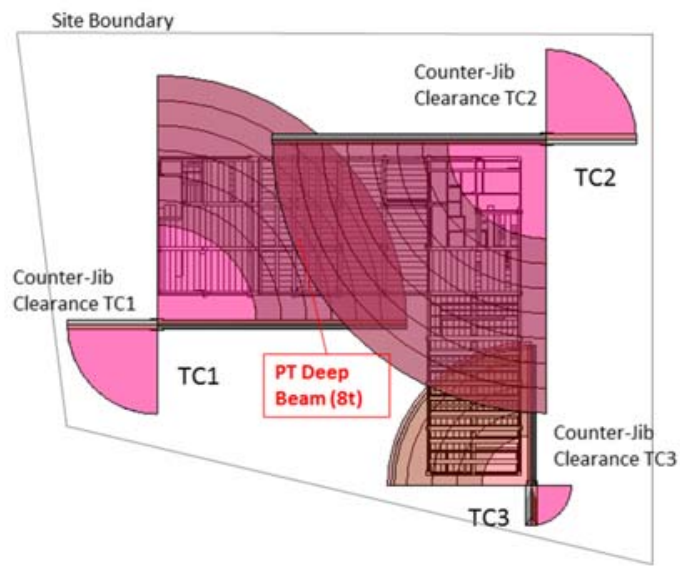

Figure 7. Plan View showing Site Boundary, CIM and Deep Beam position

The crane positions are adequate, with no clashes occurring between the counter-jib clearances. Also, the coverage requirement is met, with all elements within the workspace envelopes.

The 8 ton deep beam is situated at the intersection of the workspace envelopes of TC1 and TC2. An inspection of the load capacities of the discretized workspace envelopes reveals TC2 does not have adequate capacity to hoist. However, TC1 is found to be adequate.

\subsection{Requirement 3, 4 and 5: Jib Height Separation, Building Height Separation and Crane Height Limit}

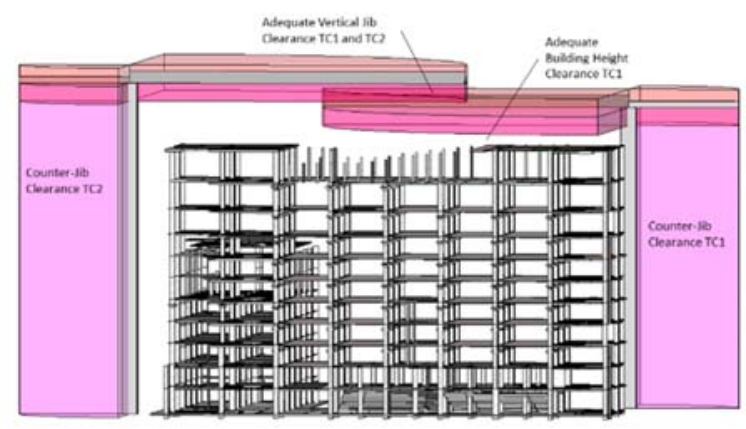

Figure 8. Elevation View

Inspecting the elevation view of the model (Figure 8), TC1 and TC2 fulfills the requirement of minimum jib height separation. Also, TC1 meets the minimum building height separation from the 10 story block. Similarly, TC3 meets the building height separation requirement from the 6 story carpark. The total height of the cranes was also found to be adequately within the permissible site limit.

\section{Conclusion}

This paper addresses several challenges associated with automating the compliance of Crane Lifting Plan requirements. The research contributions of this paper include the formalization of crane requirements for analysis. Two types of crane requirements are identified: spatial requirements and parametric requirements. Both requirement types encompass the necessary failure conditions for non-compliance of the crane requirement.

The second research contribution is the development of a Crane Information Model. CIM maps the crane geometry to its spaces, and also incorporates information like the load capacity and reach. This model is parametric and easily modifiable, allowing different crane types to be represented. This also allows it to be embedded within existing BIM systems. The advantage is that the crane information need not be 'hard coded', and a certain amount of flexibility is available to quickly evaluate alternative crane configurations.

The value of the developed framework is it provides the foundation for automated checking of crane layout planning requirements. This automation reduces both the time taken, as well as the errors made, providing an advantage for planners as well as regulatory agencies checking the CLP for compliance.

Extensions to the CIM are possible. The requirements in this paper are not exhaustive, and many other requirements exist. One example is the dismantling requirements of the crane, which has not been considered. Also, requirements which cannot be measured, cannot be captured by the framework. These include requirements like maintenance and safety checks. Future work include extending the CIM for mobile cranes, as well as developing an optimization method that integrates the flexibility of the proposed approach to determine optimal crane configurations onsite.

\section{References}

[1] M. Al-Hussein, M. Athar Niaz, H. Yu, H. Kim, Integrating $3 \mathrm{D}$ visualization and simulation for tower crane operations on construction sites, Autom. Constr. 15 (2006) 554-562. doi:10.1016/j.autcon.2005.07.007.

[2] A. Shapira, M. Simcha, Identification and Analysis of Factors Affecting Safety on Construction Sites with Tower Cranes, J. Constr. Eng. Manag. 135 (2009) 307-318. doi:10.1061/(ASCE)07339364(2009)135:4(307). 
[3] Workplace Safety and Health Report 2014, A report by the Workplace Safety and Health Institute Singapore, 2015.

[4] A. Shapira, M. Simcha, M. Goldenberg, Integrative model for quantitative evaluation of safety on construction sites with tower cranes, J. Constr. Eng. Manag. 138 (2012) 1281-1293. doi:10.1061/(ASCE)CO.1943-7862.0000537.

[5] Code of Practice on Safe Lifting Operations in the Workplaces, Workplace Safety and Health Council, 2011.

[6] M. Al-Hussein, S. Alkass, O. Moselhi, DCRANE: a database system for utilization of cranes, Can. J. Civ. Eng. 27 (2000) 1130-1138. doi:10.1139/100-039.

[7] D.R. Riley, V.E. Sanvido, Patterns of Construction-Space Use in Multistory Buildings, J. Constr. Eng. Manag. 121 (1995) 464-473.

[8] B. Akinci, M. Fischer, J. Kunz, R. Levitt, Representing Work Spaces Generically in Construction Method Models, J. Constr. Eng. Manag. $128 \quad$ (2002) 296-305. doi:10.1061/(ASCE)07339364(2002)128:4(296).

[9] B. Akinci, M. Fischer, R. Levitt, R. Carlson, Formalization and Automation of Time-Space Conflict Analysis, J. Comput. Civ. Eng. 16 (2002) 124-134. doi:10.1061/(ASCE)08873801(2002)16:2(124).

[10] S.J. Guo, Identification and resolution of work space conflicts in building construction, J. Constr. Eng. Manag. 128 (2002) 287-295. doi:10.1061/(ASCE)07339364(2002)128:4(287).

[11] D.K.H. Chua, K.W. Yeoh, Y. Song, Quantification of Spatial Temporal Congestion in Four-Dimensional Computer-Aided Design., J. Constr. Eng. Manag. 136 (2010) 641-649. doi:10.1061/(ASCE)CO.1943-7862.0000166.

[12] X. Su, H. Cai, Enabling Construction 4D Topological Analysis for Effective Construction Planning, J. Comput. Civ. Eng. (2014) 1-10. doi:10.1061/(ASCE)CP.1943-5487.0000463.

[13] X. Tan, A. Hammad, P. Fazio, Automated Code Compliance Checking for Building Envelope Design, J. Comput. Civ. Eng. 24 (2010) 203-211. doi:10.1061/(ASCE)0887-3801(2010)24:2(203).

[14] S. Malsane, J. Matthews, S. Lockley, P.E.D. Love, D. Greenwood, Development of an object model for automated compliance checking, Autom. Constr. 49 (2015) 51-58. doi:10.1016/j.autcon.2014.10.004.

[15] B.T. Zhong, L.Y. Ding, H.B. Luo, Y. Zhou, Y.Z. $\mathrm{Hu}$, H.M. Hu, Ontology-based semantic modeling of regulation constraint for automated construction quality compliance checking, Autom. Constr. 28 (2012) 58-70. doi:10.1016/j.autcon.2012.06.006.

[16] C. Huang, C.K. Wong, C.M. Tam, Optimization of tower crane and material supply locations in a high-rise building site by mixed-integer linear programming, Autom. Constr. 20 (2011) 571580. doi:10.1016/j.autcon.2010.11.023.

[17] C.M. Tam, T.K.L. Tong, GA-ANN model for optimizing the locations of tower crane and supply points for high-rise public housing construction, Constr. Manag. Econ. 21 (2003) 257-266. doi:10.1080/0144619032000049665.

[18] W.C. Hornaday, C.T. Haas, J.T. O’Connor, J. Wen, Computer-Aided Planning for Heavy Lifts, J. Constr. Eng. Manag. 119 (1994) 498-515.

[19] K. Tantisevi, B. Akinci, Transformation of a 4D product and process model to generate motion of mobile cranes, Autom. Constr. 18 (2009) 458468. doi:10.1016/j.autcon.2008.10.008.

[20] J. Irizarry, E.P. Karan, Optimizing location of tower cranes on construction sites through GIS and BIM integration, Electron. J. Inf. Technol. Constr. 17 (2012) 361-366.

[21] J. Olearczyk, M. Al-Hussein, A. Bouferguène, Evolution of the crane selection and on-site utilization process for modular construction multilifts, Autom. Constr. 43 (2014) 59-72. doi:10.1016/j.autcon.2014.03.015.

[22] M. Marzouk, A. Abubakr, Decision support for tower crane selection with building information models and genetic algorithms, Autom. Constr. $61 \quad$ (2015) 1-15. doi:10.1016/j.autcon.2015.09.008.

[23] J. Wang, X. Zhang, W. Shou, X. Wang, B. Xu, M.J. Kim, et al., A BIM-based approach for automated tower crane layout planning, Autom. Constr. $\quad 59 \quad$ (2015) 168-178. doi:10.1016/j.autcon.2015.05.006.

[24] Y. Song, D.K.H. Chua, Modeling of Functional Construction Requirements for Constructability Analysis, J. Constr. Eng. Manag. 132 (2006) 1314-1326. doi:10.1061/(ASCE)07339364(2006)132:12(1314).

[25] K.W. Yeoh, D.K.H. Chua, Representing Requirements of Construction from an IFC Model, in: Comput. Civ. Build. Eng. 2014, American Society of Civil Engineers, 2014: pp. 331-338. doi:doi:10.1061/9780784413616.042. 
Table 2. Representation of Common CLP Requirements

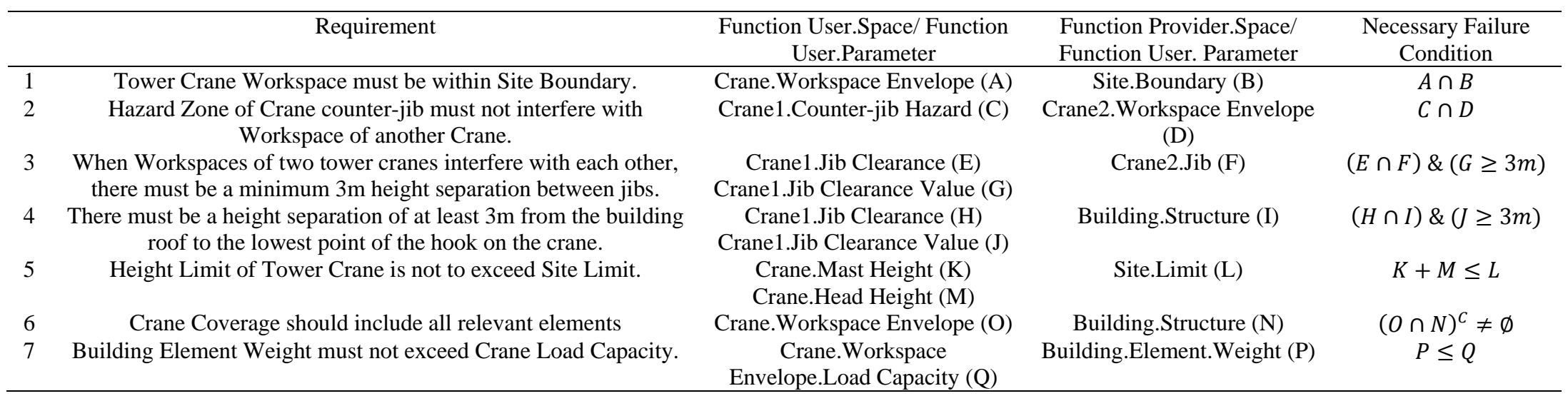

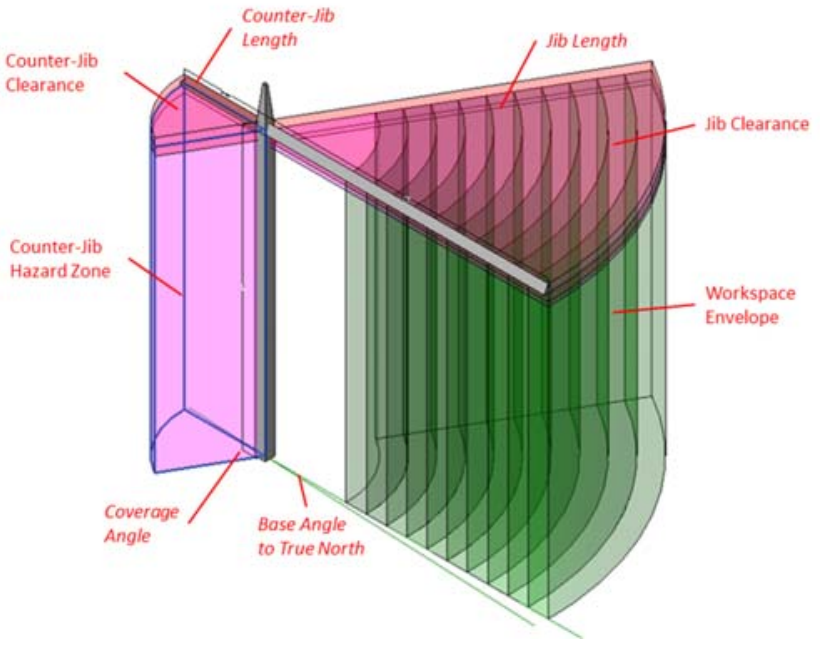

(a) Tower Crane

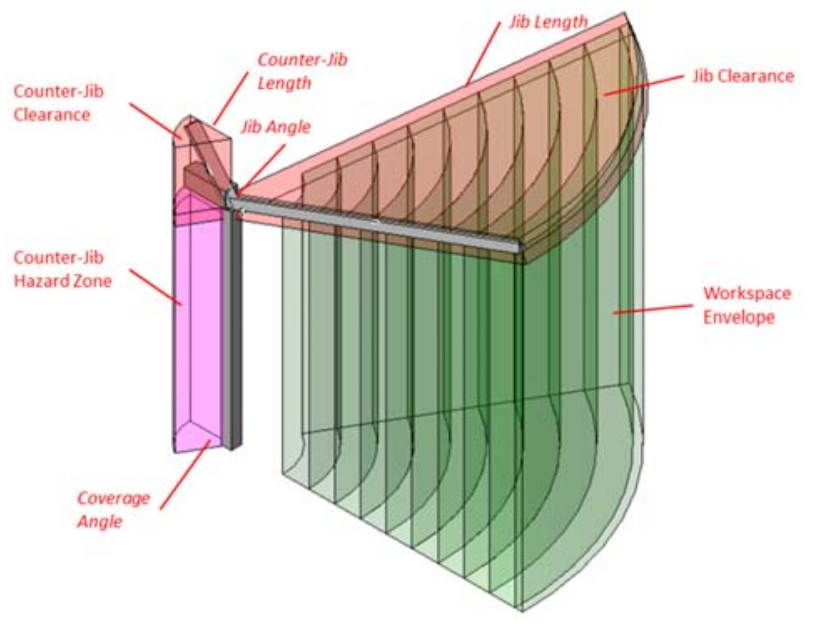

(b) Luffing Jib Tower Crane

Figure 9. Parameters and Spaces in Tower Crane and Luffing Jib Tower Crane CIM 